\title{
RUBRIEKEN
}

REVIEW ESSAY

\section{Kan de bestuurskunde de democratie redden?}

\author{
Ringo Ossewaarde
}

A Theory of Governance. Door Mark Bevir (London: University of California Press, 2013), 263 pp.

(Re)Imagining Humane Global Governance. Door Richard Falk (London: Routledge, 2014), 198 pp.

Cosmopolitan Commons: Sharing Resources and Risks across Borders. Door Nil Disco and Eda Kranakis (red.) (London: The MIT Press, 2013), 345 pp.

Het debat over het verval en het mogelijke voortbestaan, of revitalisering, van de democratie is ongetwijfeld het meest belangrijke in het bestuurskundige discours van de afgelopen decennia. Het debat gaat over de betekenis van de democratie, de ontwikkeling en het verval van de democratie, en de problematische verhouding van de democratie tot het wereldwijde kapitalisme in het algemeen en het neoliberalisme en nieuw publiek management (NPM) in het bijzonder. Over de betekenis van de democratie zijn bestuurskundigen verdeeld. Voor de één is de democratie een technisch systeem van procedures waarin macht, bovenal uitvoerende macht, wordt gereguleerd. De democratie betreft hier een democratische rechtstaat. Voor de ander refereert het begrip democratie naar een democratische cultuur, waarin bestuurders de opdracht hebben om mensen te vormen of humaniseren tot democratische wezens die democratisch denken, voelen en handelen, binnen en vooral ook buiten gestelde kaders. Over het verval van de democratie in de afgelopen decennia is meer consensus te vinden in wetenschappelijke discussies, zeker als wordt gekeken naar titels van belangwekkende publicaties zoals Colin Crouch's Post-Democracy en Donatella Della Porta's Can Democracy Be Saved? Neoliberaal beleid, met haar nadruk op productie, kostentoedeling, prestatiemeting en afrekenen, zo luidt de dominante redeneertrant, is de grote plaag voor de hedendaagse democratie. Mark Bevir, Richard Falk, en Nil Disko en Eda Kranakis bieden elk een eigen bijdrage aan het debat over mogelijke revitalisering van de democratie, waarbij ze allemaal een pleidooi houden voor een multidisciplinaire benadering van bestuur en revitalisering van de bestuurskunde zelf, omwille van de democratie.

Het vertrekpunt van Bevirs A Theory of Governance is dat 'democratisch bestuur een dringende kwestie is. Opeenvolgende fasen van publieke sector hervormingen hebben geleid tot zorgen over de staat van de democratie' (p. 187). Deze hervormingen worden geduid in termen van het door Bevir verafschuwde nieuw publiek management, dat volgens hem een bestandsdeel is van een naargeestig neolibe- 
raal discours (Bevir gebruikt zelf de term 'narratief'). In het neoliberaal discours wordt het bestuur begrepen 'in termen van toenemende doelmatigheid zogenaamd gebracht naar de publieke sector door te vertrouwen op markten, uitbesteding, reductie van staf, en budgettering onder strikte richtlijnen' (p. 16). Ook worden performance management en netwerkmanagement (p. 148) genoemd als bestandsdelen van het neoliberale discours. Kenmerkend voor het neoliberaal discours, met haar bestandsdelen, is dat zij berust op modernistische (instrumentalistische) wetenschappelijke veronderstellingen. En juist die veronderstellingen hebben het democratisch verval ingeluid. Anders gezegd: de modernistische bestuurskundige is de antidemocraat. 'Wanneer sociale wetenschappers vertrouwen op modernistische expertise, dan bekrachtigen zij een vals geloof in de formele expertise ten koste van een meer dialogische en democratische ethos', stelt Bevir (p. 11). De modernistische veronderstellingen zijn terug te vinden in 'positivistische theorieën' (p. 16) - bron van alle kwaad in de bestuurskunde. Het positivisme komt bovenal tot uitdrukking in de rationele keuzetheorie en in de netwerktheorie. Deze theorieën, die veelal met elkaar worden verbonden, voeden het neoliberale discours met vooringenomen assumpties over rationaliteit en formele modellen waarmee de alledaagse werkelijkheid van besturen grof geweld wordt aangedaan. Bovendien dreigt met deze modernistische theorieën de rijke intellectualiteit en democratische cultuur van de bestuurskundige af te sterven: 'de studie van het bestuur loopt het gevaar om te verworden tot het rijk van saaie technici' (p. 34). En saaie technici kunnen geen democratische cultuur vormgeven. Saaie technici vormen saaie technische beheerssystemen.

A Theory of Governance is een boek over het anti-neoliberale, anti-positivistische, pro-academische en prodemocratische 'gedecentreerde alternatief' (p. 23). Bevirs gedecentreerde theorie biedt een visie van 'bestuur na het neoliberalisme' (p. 149). De gedecentreerde theorie rust op drie, innig met elkaar verbonden, pijlers. Ten eerste is zij post-fundamenteel, in de zin dat zij weigert om organisaties en instituties te reduceren tot interveniërende variabelen (p. 25). Post-fundamentalisten zoals Bevir baseren hun inzichten vooral op 'bottom-up studies over de wijzen waarin vormen van bestuur worden gecreëerd, ondersteund, en getransformeerd door de wisselwerking en strijd tussen de betekenissen die zijn ingebed in menselijke activiteit' (p. 25). Ten tweede wordt in de gedecentreerde theorie, in overstemming met het post-fundamentalisme, de nadruk gelegd op 'de contingente en betwiste aard van alle wijzen van bestuur' (p. 26). Alle vormen van bestuur zijn historisch contingent, in de zin dat actoren worden beïnvloed door tal van gebruiken, tradities en ideologieën die hen inspireren om zaken op geheel eigen wijze aan te pakken. Alle vormen van bestuur zijn betwistbaar, in de zin dat er geen inherente correcte antwoorden op maatschappelijke problemen voor handen zijn, zelfs niet binnen een bepaalde gedeelde traditie of ideologie (p. 48). Ten derde gaat de gedecentreerde theorie uit van de gesitueerde agent, die is ingebed in specifieke historische, sociale, economische, politieke en culturele contexten. De gesitueerde agent, bijvoorbeeld een ambtenaar of een bestuurskundige, handelt op basis van overtuigingen die voortkomen uit geërfde tradities en ideolo- 
gieën, om een antwoord te vinden op dilemma's. Nieuwe overtuigingen leiden tot nieuwe handelingen (p. 5).

De gedecentreerde theorie staat hiermee lijnrecht tegenover de rationele keuzetheorie en de netwerktheorie. Tegen de rationele keuzetheorie stelt Bevir dat een actor nimmer primair berekend handelt en nooit autonoom kan zijn. Actoren worden gekenmerkt door creativiteit en handelen op basis van hun verbeeldingskracht en overtuiging - daarmee zijn zij per definitie afhankelijk van hun culturele erfenis of contingente tradities. Bij Bevir duidt het begrip 'theorie' niet op een formeel model, een techniek of een mechanisme van bestuur. Integendeel, een theorie is een academisch narratief die wordt gekenmerkt door 'een brede verscheidenheid aan strijdige en concurrerende details' (p. 163). Tegenover de netwerktheorie biedt de gedecentreerde theorie het radicale inzicht van bestuur als 'iets dat lijkt op een politieke wedstrijd gebaseerd op strijdende en contingente verhalen' (pp. 26-27). In de gedecentreerde theorie zijn netwerken platforms van contingente strijd over macht en verzet (p. 107). Dit betekent dat er geen specifieke of universele gereedschapskist bestaat voor het managen van netwerken. Bevir verschuift dan ook de aandacht van managementstijlen, technieken, instrumenten en strategieën naar het vertellen van, en luisteren naar, verhalen over bestuur (p. 31). De bestuurskundige studie van het openbaar bestuur betreft niet de ontwikkeling van formele modellen, maar bestaat uit het vertellen van verhalen over de overtuigingen van mensen. Bestuurskunde 'gaat over het verschaffen van narratieven over de narratieven van andere mensen' (p. 69).

De hoop van Bevir is dat bestuurskundigen academische, intellectueel hoogwaardige verhalen - ofwel, de 'radicale perspectieven' (p. 167) - kunnen bieden. Met zo'n anti-instrumentalistische bestuurskunde worden dan niet zo zeer nieuwe beleidsinstrumenten of beheersapparaten ontwikkeld omwille van systeemhandhaving, maar kunnen 'democratische idealen' (p. 148) worden herontdekt. Deze idealen, gevoed door een herboren, post-fundamentele bestuurskunde, voeden hernieuwde politieke overtuigingen van politici, ambtenaren en burgers die het vervloekte neoliberale discours uiteindelijk zouden kunnen ombuigen. Bevir benadrukt echter dat 'de heropleving van democratische idealen' niet mogelijk is binnen de gevestigde bestuurlijke systemen en grootschalige bureaucratieën ( $p$. 205). Democratische idealen worden verpletterd in modernistische constructies. Democratische idealen, zo luidt zijn verwachting, in navolging van de socioloog $C$. Wright Mills, leven op in kleinschalige Socratische dialogen. Democratische revitalisering ontpopt zich in 'mini-publieken, deliberatieve peilingen, en deliberatieve planning' (p. 188); en in de meent (commons), in kleinschalige, lokale zelforganisatie en zelfbestuur - bijvoorbeeld in het beheer en verdeling van natuurlijke bronnen, zoals aardgas (p. 200). Kortom, volgens Bevir is het uiteindelijke doel dat de bestuurskunde dient - een dienen dat mogelijk wordt gemaakt door de gedecentreerde theorie - het humaniseren van mensen. Het is de taak van bestuurskundigen om, met hun academische narratieven, mensen cultureel te vormen tot democratische wezens, die uiteindelijk in staat zijn om op intellec- 
tuele wijze te redeneren met elkaar en zich daarmee te onttrekken aan de modernistische veronderstellingen die aan het neoliberale discours ten grondslag liggen.

A Theory of Governance is een helder geschreven boek met een duidelijke opdracht voor bestuurskundigen en urgentie om de bestuurskunde te vernieuwen, omwille van het stoppen van verder democratisch, cultureel verval. Bevir argumenteert goed en zijn strijd lijkt mij juist. Bovendien is hij consistent in het theoretisch doorredeneren van de decentratie: niet alleen het openbaar bestuur maar ook de natie is een gedecentreerd verschijnsel (p. 82). Zeker in een context van globalisering en wereldwijd kapitalisme verwordt de natie tot een transnationaal, gedifferentieerd en discontinu complex van verhalen die de nationale eenheid doet fragmenteren en de pluraliteit van groepen, met hun eigen verhalen, tot uitdrukking laat brengen (p. 89). Ofwel, een gedecentreerde natie is een natie zonder nationalisme. Het is een kosmopolitische natie die intellectueel en emotioneel is uitgerust om de uitdagingen van een globaliserende wereld, met haar overlappende jurisdicties, territoria en bestuurlijke niveaus (p. 163), aan te gaan. Dat wil niet zeggen dat Bevirs boek geen minpunten heeft. Integendeel, A Theory of Governance staat bol van de zelf-geconstrueerde dichotomieën, oppervlakkige stelligheid en clichés. Om een voorbeeld te noemen, Bevir beweert dat 'twintigsteeeuwse sociale wetenschap werd gedomineerd door twee varianten van modernisme', te weten, positivisme (utilisme, rationale keuze theorie) en functionalisme (institutionalisme, netwerktheorie, en communitarisme) (p. 134). Hoe begrijpelijk deze stelling ook is in het licht van Bevirs argumentatie, gaat hij onterecht voorbij aan de invloed die de interpretatieve benadering van Max Weber en het marxisme hebben gehad, om maar te zwijgen over de populariteit van wetenschappers als Norbert Elias, Michel Foucault en Pierre Bourdieu. Een ander punt van kritiek betreft Bevirs gebruik van de bestuurskundige literatuur en reconstructie van bestuurskundige debatten. Zowel de literatuur die hij aanhaalt als de kwesties die hij reconstrueert stammen vooral uit de jaren negentig. Bij de kritische lezer roept dit de vraag op waarom dit boek niet twintig jaar eerder is gepubliceerd - zeker gezien de vele discussies over democratische revitalisering en de rol van mini-publieken, de meent en sociale bewegingen in de sociologie van de afgelopen twintig jaar.

(Re)Imagining Humane Global Governance, een verzameling van Falks recente essays, heeft dezelfde betrokkenheid als A Theory of Governance. De twee werken delen dezelfde intellectuele bron, te weten het gedachtegoed van C. Wright Mills. Bevir en Falk delen dan ook eenzelfde begrip van democratie, met daaraan gekoppeld de democratische opdracht voor bestuurskundigen. Bevir en Falk hebben dezelfde vijanden: het neoliberalisme en het modernisme - beiden houden het neoliberalisme verantwoordelijk voor het hedendaagse verval van democratische cultuur. Echter, in tegensteling tot Bevir is het bestuurskundige verhaal van het bestuur bij Falk nauw verbonden met het vraagstuk van internationale betrekkingen. Bij hem wordt het bestuur nadrukkelijk in een globaliseringsperspectief geplaatst. Anders dan Bevir typeert Falk het neoliberalisme dan ook niet in termen van binnenlandse beleidshervormingen en NPM, maar als een verschijnsel 
van de nieuwe wereldorde van na de Koude Oorlog. Falk duidt het neoliberalisme onder de noemer van de 'Washington consensus' (p. 14), met haar nadruk op zaken als begrotingsdiscipline, marktbepaalde rentetarieven, concurrerende valutakoersen, handelsliberalisatie en liberalisatie van buitenlandse directe investeringen, en wereldwijde regulering van eigendomsrechten. Het probleem van het neoliberaal beleid is volgens Falk dat zij een inhumaan of barbaars bestuur vormgeeft die wordt gekenmerkt door 'het primaat verschaft aan de veiligheid van staten, in het bijzonder aan dominante staten, en aan het veilig stellen van de voorwaarden voor de grenzeloze doelmatigheid van kapitaal met betrekking tot handel en investeringen' (p. 3). Als gevolg van dit neoliberale primaat ontstaat volgens Falk een 'apocalyptische' toestand, in de zin dat wereldbedreigende, dehumaniserende kwesties niet serieus worden opgepakt (p. 1). Zie hier het monster van de Washington consensus.

Terwijl Bevir een gedecentreerde theorie presenteert als democratisch alternatief voor modernistische, en nauw met het neoliberale discours verbonden, perspectieven op bestuur, biedt Falk humaan bestuur als alternatief voor de Washington consensus. Humaan bestuur, een concept dat hij in een eerder werk (On Humane Governance, 1995) reeds heeft geïntroduceerd, is 'toegewijd aan de veiligheid van mensen en de ontwikkeling van mens-georiënteerde paradigma's, die prioriteit geven aan voedsel, water, gezondheid, en werkzekerheid, in plaats van de verwachtingen vervullen van miljardair durfkapitalisten en hedgefonds managers' ( $p$. 3). Falks concept van humaan bestuur wordt gekenmerkt door de hervorming van 'een uitgerangeerd Westfaals raamwerk' (p. 88): humaan bestuur en het centrisme van de zogenaamde soevereine staat gaan niet samen. 'De volharding van het Westfaalse systeem van soevereine staten compliceert de vorming van effectieve antwoorden op mondiale beleidsuitdagingen die grootschalige bijstellingen in het denken, handelen, en verdeling van hulpbronnen vereisen' (p. 95). Falk benadrukt dat soevereiniteit het kernconcept is van het modernistische denken. Humaan bestuur vereist dan ook nadrukkelijk een post-fundamentele wijze van denken over staat, samenleving en wereld. Bij humaan bestuur ligt het primaat niet bij het staat, en zelfs niet bij de mensenrechten, maar bij 'ethische en ecologische imperatieven' (p. 69). Bij humaan bestuur zijn alle actoren, ook de staat, gebonden aan deze imperatieven, door Hans Jonas in de Categorical Imperative (1984) geformuleerd, om morele verantwoordelijkheid, op ruimdenkende en groothartige wijze, voor het voorbestaan van de wereld te kunnen waarborgen. Humaan bestuur is gebaseerd op zachte machtsbeginselen van diplomatie in plaats van een militaristische framing van veiligheidsbeleid (pp. 37-38). Volgens Falk is humaan bestuur het enige alternatief voor de Washington consensus om de apocalyptische toestand nog om te kunnen buigen (p. 78).

Maar net als Bevir heeft Falk, in navolging van C. Wright Mills, geen vertrouwen in de wijsheid, intelligentie en moraal van de bestuurlijke elites die de topposities van deze wereld innemen. Deze zijn bepaald niet gecommitteerd aan democratische idealen van humanisering en hebben zo hun eigen belangen. Om zelf maar niet te corrumperen, en te voorkomen dat de bestuurskunde een instrument van 
de uitvoerende macht wordt, zal de bestuurskundige zich verre moeten houden van de machtshebbers. De vormgeving van humaan bestuur is een activistisch bottom-up proces (p. 46; p. 101) - in dat proces ligt de democratische opdracht van de bestuurskundige. 'Slechts de mobilisatie van transnationale krachten, globalisering van onderop als een initiële uitdrukking van oppositie tegen het beleid en normatieve falen van een uitgerangeerd Westfaals raamwerk, kan een nieuw publiek bewustzijn creëren dat geleidelijk aan het elite denken en handelen infiltreert, en het reconstrueert' (p. 88). Falk vestigt hierbij zijn hoop op protestbewegingen die voortkomen uit de anti-slavernijbeweging, het antikolonialisme, en de anti-apartheidbeweging. Dit zijn bewegingen die de logica van superieure militaire en materiële macht hebben weerstaan (p. 178). Falk, zelf een Amerikaanse Jood en van 2008-2014 rapporteur van de VN Mensenrechtenraad voor de Palestijnse gebieden, ziet de Palestijnse Solidariteitsbeweging nadrukkelijk als de opvolger van de anti-apartheidbeweging (p. 176). Hij benadrukt, in navolging van Edward Saïd, dat het Westfaalse systeem en de VN het Palestijnse volk 'minder dan zero' heeft geboden en haar heeft laten verrekken (p. 60) - een hoogst barbaarse uitdrukking van inhumaan, onverantwoordelijk, immoreel bestuur. Falk roemt ook de Occupy beweging als een uitdrukking van wereldwijde maatschappelijke waakzaamheid en lokale grassroots activisme (p. 114). Uit dergelijke bewegingen kunnen nieuwe, kosmopolitische publieken (p. 48) en 'wereldwijde meent' (p. 149) ontstaan, gevoed door een betrokken bestuurskunde, die de grote bestuurlijke kwesties van radicale denuclearisering, opwarming van de aarde, het verminderen van harde macht, en de verspreiding van democratische, humaniserende idealen, nieuw leven kunnen inblazen (pp. 149-150).

Net als in Bevirs A Theory of Governance, wordt ook in Falks (Re)Imagining Humane Global Governance de bestuurskundige een spiegel voorgehouden. Ook aan dit werk ligt impliciet de vraag ten grondslag waarvoor bestuurskundige kennis dient en welke taak de bestuurskundige heeft in de theoretisering en vormgeving van bestuur. In Falks boek wordt uiteengezet wat de belangwekkende bestuurskundige vraagstukken zijn waar bestuurskundigen zich op zouden moeten richten, indien ze niet in trivialiteiten en banaliteiten wensen te vervallen, of verworden tot saaie technici. Falk houdt een geloofwaardig en zeer welkom pleidooi voor een nieuwe bestuurskundige kijk op het bestuur, die bestuurskundigen dwingt om het bestuur te duiden in een context van verschuivende internationale betrekkingen en globaliseringsprocessen. Re)Imagining Humane Global Governance heeft zonder meer ook zwakkere punten. Falk schrijft wel erg uit de losse pols en theoretiseert bepaald niet sterk. Hij put vooral uit zijn eigen schat aan kennis en ervaring uit een zeer lange academische loopbaan, waarbij hij te weinig engagement toont met de werken van zijn collega's of met recente literatuur. Reconstructie van relevante hedendaagse debatten over de democratische malaise, bestuurlijke innovatie en kosmopolitanisme laat hij jammer genoeg achterwege, waarmee Re)Imagining Humane Global Governance toch een bepaalde intellectuele diepgang mist - een diepgang die Falk in eerdere werken zoals On Humane Governance, zeker wel heeft laten zien. 
Zowel Bevir als Falk zien een belangrijke rol voor de meent weggelegd in hun alternatief voor neoliberaal bestuur, te meer omdat de meent de neoliberale regimes van eigendomsrechtrechten ter discussie stelt. Met name sinds Elinor Ostrom's Governing the Commons (1990) is de belangstelling en bewustwording van de meent als bestuurlijk verschijnsel, als alternatief voor het beheer van hulpbronnen buiten de machten van de staat en de markt, de afgelopen 25 jaar aanzienlijk toegenomen, vooral met de opkomst van digitale commons, zoals Internet, Wikipedia, open source software, en digitale munteenheden zoals bitcoin. Disco en Kranakis' Cosmopolitan Commons is een geredigeerd boek waarin diverse geschiedkundige bijdragen worden geleverd aan het huidige debat over de rol van de meent voorbij de neoliberale ordeningen. Net als Bevir keren de auteurs zich tegen onhistorische, abstracte benaderingen van bestuur in het algemeen en van commons in het bijzonder. Zij pogen 'de theorie van de meent te historiseren' (p. 2), waarbij steeds de technologische factor in moderne commons wordt benadrukt. En net als Falk streven Disco en Kranakis erna om 'voorbij de rationalistische-etatistische concepties van internationale betrekkingen' van het Westfaalse systeem te gaan (p. 3). Anders dan bij Bevir en Falk wordt in Cosmopolitan Commons geen nieuw democratisch alternatief geboden. Sterker nog, de auteurs stellen dat de kosmopolitische, grens-overstijgende commons nauw zijn verbonden met industrialisering, internationale samenwerking, integratie en globalisering (pp. 2-3; p. 21). Ofwel, kosmopolitische commons zijn volgens de auteurs al zo oud als de moderniteit. Ze zijn onlosmakelijk verbonden met moderniseringsprocessen.

Disco en Kranakis definiëren de meent op soortgelijke wijze als Ostrom: 'een commons is een hulpbron gedeeld door een groep waar de hulpbron kwetsbaar is voor behuizing, over-gebruik en maatschappelijke dilemma's. In tegenstelling tot een publiek goed, vereist het management en bescherming om het in stand te houden' (p. 20). In deze, overigens modernistische, definitie van de meent staat het managementregime centraal: het gaat om het valoriseren en het beschermen van de hulpbron (p. 22). De meent is hiermee een vorm van bestuur die alleen kan bestaan als gebruikers van de hulpbron in kwestie regels ontwerpen over hoe de hulpbron te managen en deze te delen in het gebruik - ofwel, volgens Disco en Kranakis bestaat de meent door de ontwikkeling van een 'morele economie' ( $\mathrm{p}$. 24). De historische ontwikkeling van morele economieën - normatieve beheersystemen die worden gekenmerkt door reciprociteit, samenwerking, wederzijdse hulp, delen van bronnen, risico's en verantwoordelijkheden afgemeten aan de behoeften van de gebruikersgemeenschap (in plaats van het recht of beleid) ( $p$. 42 ) - is het centrale aandachtspunt in de wijze waarop in Cosmopolitan Commons de commons wordt bestudeerd. Het kosmopolitische in de (moderne) commons (anders dan premoderne, lokale commons als bosbeheer) zit hem volgens de auteurs erin dat kosmopolitische commons 'floreren in de ruimte tussen (aan de ene kant) natiestaten' verbreding van grensbewaking en nationale soevereiniteit en (aan de andere kant) de meer expansieve ondernemingen die technisering toestond, en welke kapitalisten en anderen verlangden' (p. 23). De commons die in de hoofdstukken van Cosmopolitan Commons worden onderzocht betreffen dan 
ook 'bronruimten die de nationale soevereiniteit transcendeerden en toch uitdaagden' (p. 24), zoals bijvoorbeeld het luchtruim (door Eda Kranakis), radiospectrum (door Nina Wormbs), en de weersvoorspelling (door Paul Edwards). Industriële technologie speelt steeds een centrale rol in de ontwikkeling en beheer van dergelijke commons.

Hoewel het vertrekpunt van Cosmopolitan Commons niet zo zeer de democratische malaise maar het historische tekort onder bestuurskundigen betreft, benadrukken Disco en Kranakis wel dat kosmopolitische commons 'essentiële bouwstenen van ecologische en maatschappelijke duurzaamheid' vormen (p. 46). Net als Falk benadrukken Disco en Kranakis de beperkingen van het Westfaalse systeem: verschijnselen als radio-uitzending of luchtvervuiling snijden dwars door nationale grenzen heen (p. 24). Dit is wat dergelijke verschijnselen kosmopolitisch maakt. Tegelijkertijd wordt in de casushoofdstukken van Cosmopolitan Commons duidelijk dat de nationalistische aspiraties van natiestaten bedreigend zijn voor de commons. Zo geeft Kranakis aan dat de succesvolle ontwikkeling van het luchtruim na het Verdrag van Parijs (1919), met reeds 45 miljoen jaarlijkse passagiersmijlen in 1929, teniet dreigde te gaan aan de nationalisering van het luchtruim door oorlogvoerende staten (p. 70). Worms legt uit dat het radiospectrum en de verdeling van frequenties ten onder ging gedurende de Tweede Wereld Oorlog (p. 109). En Håkon With Andersen beschrijft hoe de Noordzee, als een transnationale bron van visserij, werd genationaliseerd als staatseigendom op het moment dat er gas en olie kon worden geboord (p. 266). Kristiina Korjonen-Kuusipuro beschrijft hoe een binationaal beheer van de rivier de Vuoksi, gebaseerd op een gedeelde morele economie, juist eraan bijdroeg om wederzijdse vijandigheid en wantrouwen tussen Finland en Rusland van na de oorlog te overwinnen (p. 139). Van alle hoofdstukken beschrijft Tiago Saraiva nog wel het meest het democratische potentieel van kosmopolitische commons. Toen experts een zadengewelf in een berg in Noorwegen openden, in 2008, om de biodiversiteit van gewassen te beschermen, protesteerden boeren tegen deze centralisatie van expertise en beheer. Door decentralisatie van gen-banken werd de relatie tussen fokkers en lokale boeren hersteld - en was de gen-bank commons, met de bottom-up participatie van boeren, niet langer 'een exclusieve wetenschappelijke informatie commons' (p. 206).

Cosmopolitan Commons biedt boeiende historische verhalen over de ontwikkeling van specifieke commons die vaak over het hoofd worden gezien in de commons literatuur. Hiermee verrijken de auteurs nadrukkelijk de verbeelding, te meer daar de auteurs de commons nadrukkelijk bezien als essentiële sociale arrangementen in onze huidige wereld (en beslist niet als 'exotische sociale verschijnselen' (p. 327)). Disco en Kranakis herinneren bestuurskundigen eraan dat zij vooral ook erudiet moeten zijn: geen hoogwaardige bestuurskunde is mogelijk zonder een behoorlijke dosis historische kennis. En hierin schiet de bestuurskunde zonder twijfel tekort, hier moet nog heel hard gewerkt worden. Cosmopolitan Commons is niet zonder zwakten. Het betreft hier een geredigeerd boek, het resultaat van een omvangrijk onderzoeksproject, dat door technologiehistorici is geschreven, wiens verhouding tot de gevestigde commons debatten in het boek beperkt blijkt. Zoals 
de auteurs zelf aangeven is er gekozen voor een 'commons aanpak' bij hun project (p. 11). Dit geeft de kritische lezer al snel het gevoel dat de, overigens zeer beperkte, theoretisering van de meent er achteraf bij is gehaald door de redactie, nadat het historische onderzoek reeds was verricht. De cases staan nogal los van het theoretische perspectief - dit is vaak een probleem met geredigeerde werken dat is geschreven door meerdere auteurs. Wat geldt voor de theoretisering van de meent geldt ook voor de theoretisering van het kosmopolitanisme, dat in het boek te weinig wordt onderscheiden van verschijnselen als internationalisme en transnationalisme. In de werken van auteurs als David Held en Ulrich Beck, waar Disco en Kranakis hun inspiratie uit putten zoals zij zelf aangeven (p. 2), is kosmopolitanisme een nieuw verschijnsel dat een hedendaagse transformatie van de moderniteit illustreert - een transformatie die ook het modernisme en modernistische theorieën intellectueel bankroet maakt. Volgens Held en Beck is het kosmopolitanisme bepaald geen verschijnsel dat zou zijn terug te vinden in de eerste helft van de twintigste eeuw, zoals Disko en Kranakis beweren, maar bovenal een democratisch alternatief voor het gehate neoliberalisme waarin de democratie ondergeschikt wordt gemaakt aan financiële machten. Deze kritiek neemt echter niet weg dat er voor bestuurskundigen veel valt te leren in Cosmopolitan Commons, vooral in de zoektocht naar verbeeldingskracht voor bestuurskundige vernieuwing in tijden van democratische malaise.

De werken van Bevir, Falk, en Disko en Kranakis bieden bestuurskundigen de broodnodige verbeeldingskracht om hun perspectief te verruimen in dialoog met diverse academische disciplines, en hun theorieën te historiseren. Het zijn uitnodigingen om bestuurskundigen, en bestuurskundig onderzoek, reflexief in een historische, internationale en globaliserende context te plaatsen. In zo'n dynamische wereld zal de bestuurskunde zichzelf voortdurend moeten vernieuwen om haar belofte te kunnen blijven waarmaken. En die belofte, zo benadrukken met name Bevir en Falk, de enige legitieme bestaansgrond van bestuurskundigen, is het bieden van inzichten waarmee een democratische cultuur levend kan worden gehouden. En dit tegen alle antidemocratische wetenschappelijke (modernisme) en bestuurlijke (neoliberalisme) tendensen in. Daarmee krijgt de intellectuele, humaniserende arbeid van bestuurskundigen het karakter van strijd. 